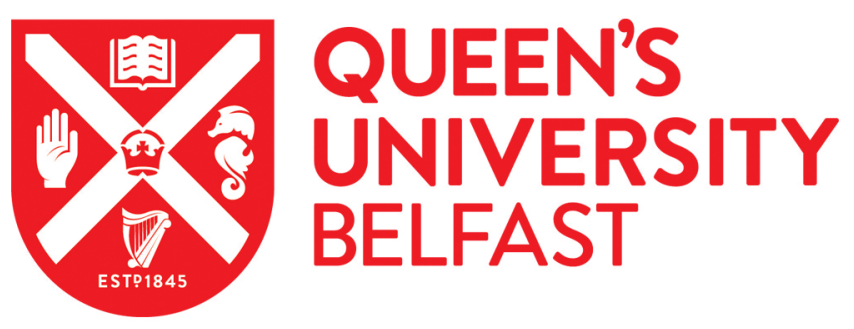

\title{
Relative Contribution of Lipids and apolipoproteins to incident coronary heart disease and ischemic stroke the PRIME study
}

\begin{abstract}
Canoui Piitrine, F., Luc, G., Bard, J. M., Ferrieres, J., Yarnell, J., Arveiler, D., Morange, P., Kee, F., Evans, A., Armouyel, P., Ducimetiere, P., \& Empana, J. P. (2010). Relative Contribution of Lipids and apolipoproteins to incident coronary heart disease and ischemic stroke the PRIME study. Cerebrovascular Diseases, 30(3), 252259. https://doi.org/10.1159/000319067
\end{abstract}

Published in:

Cerebrovascular Diseases

Queen's University Belfast - Research Portal:

Link to publication record in Queen's University Belfast Research Portal

\section{General rights}

Copyright for the publications made accessible via the Queen's University Belfast Research Portal is retained by the author(s) and / or other copyright owners and it is a condition of accessing these publications that users recognise and abide by the legal requirements associated with these rights.

Take down policy

The Research Portal is Queen's institutional repository that provides access to Queen's research output. Every effort has been made to ensure that content in the Research Portal does not infringe any person's rights, or applicable UK laws. If you discover content in the Research Portal that you believe breaches copyright or violates any law, please contact openaccess@qub.ac.uk. 


\title{
Relative Contribution of Lipids and Apolipoproteins to Incident Coronary Heart Disease and Ischemic Stroke: The PRIME Study
}

\author{
Florence Canouï-Poitrine ${ }^{a, b} \quad$ Gerald Luc $^{c}$ Jean-Marie Bard ${ }^{d}$ Jean Ferrieres ${ }^{e}$ \\ John Yarnellj Dominique Arveiler $^{f}$ Pierre Morange ${ }^{g} \quad$ Frank Kee $^{j} \quad$ Alun Evans $^{j}$ \\ Philippe Amouyel $^{\mathrm{h}}$ Pierre Ducimetiere ${ }^{\mathrm{i}}$ Jean-Philippe Empana ${ }^{\mathrm{a}}$ \\ on behalf of the PRIME Study Group \\ aINSERM, U970, Paris Cardiovascular Research Center, Université Paris Descartes, UMR-S970, Paris, \\ b Hospices Civils de Lyon, Pôle Information Médicale Evaluation Recherche, Université Lyon 1, Lyon, \\ 'Department of Atherosclerosis, INSERM, U545, Institut Pasteur de Lille, Lille 2 University, Lille, \\ ${ }^{d}$ Faculté de Pharmacie, Université de Nantes, Nantes, ${ }^{e}$ The Toulouse MONICA Project, INSERM, U558, \\ Département d'Epidémiologie, Université Paul Sabatier, Toulouse, ${ }^{\mathrm{f}}$ The Strasbourg MONICA Project, \\ Laboratoire d'Epidémiologie et de Santé Publique, EA 3430, and Université de Strasbourg, Strasbourg, \\ gINSERM, U626, Laboratory of Hematology, La Timone Hospital, Marseille, h' The Lille MONICA Project, INSERM, \\ U744, Institut Pasteur de Lille, Université Lille Nord de France, Lille, and 'INSERM, Université Paris Sud-XI, \\ Paris, France; 'The UKCRC Center of Excellence for Public Health, The Queen's University, Belfast, UK
}

\section{Key Words}

Epidemiology $\cdot$ Coronary heart disease $\cdot$ Ischemic stroke $\cdot$

Risk factors $\cdot$ Lipids

\begin{abstract}
Aim: To compare within the same cohort the association of a large panel of lipids with the risk of incident coronary heart disease (CHD) and ischemic stroke events in participants of the Prospective Epidemiological Study of Myocardial Infarction. Methods: In this binational (Northern Ireland and France) prospective cohort, we considered 9,711 men aged 50-59 years free of CHD and stroke at baseline (1991-1993). The hazard ratios of each lipid marker for CHD and ischemic stroke events were estimated in separate Cox proportional hazard models adjusted for age, study center, systolic blood pressure, antihypertensive treatment, current smoking sta-
\end{abstract}

tus, body mass index and diabetes. Results: After 10 years of follow-up, 635 men had a first CHD and 98 a first ischemic stroke event. Total cholesterol (total-C), high-density lipoprotein cholesterol (HDL-C), low-density lipoprotein cholesterol (LDL-C), non-HDL-C, triglycerides, apolipoprotein (Apo) $A 1$ and Apo B100, their ratios and lipoprotein (a) [Lp(a)] were all significantly predictive of future CHD. Associations with ischemic stroke followed the same trend as for CHD, but with lower strength, and none were statistically significant. However, none of the differences between the hazard ratios for CHD and for ischemic stroke were statistically significant. Conclusions: In healthy, middle-aged men, total- $C, H D L-C$, LDL-C, non-HDL-C, triglycerides, Apo A1 and Apo B100, their ratios and $\mathrm{Lp}(\mathrm{a})$ are, if anything, weak predictors of ischemic stroke events over a 10-year period.

Copyright $\odot 2010$ S. Karger AG, Basel

\section{KARGER}

Fax +41 613061234 E-Mail karger@karger.ch www.karger.com
(C) 2010 S. Karger AG, Base

1015-9770/10/0303-0252\$26.00/0

Accessible online at:

www.karger.com/ced
Jean-Philippe Empana

INSERM U970

56 rue Leblanc

FR-75015 Paris (France)

Tel. +33 15398 8020, Fax +33 15398 7954, E-Mail jean-philippe.empana@inserm.fr 


\section{Introduction}

Several large randomized controlled trials have shown that cholesterol-lowering statin therapy can significantly reduce the risk of both coronary heart disease (CHD) and ischemic stroke [1-4]. While the link between lipids and CHD risk is firmly established [5-7], it is still unclear whether there is one between lipids and ischemic stroke [8]. An association between lipids and ischemic stroke has been supported by some [9-12] but not all observational studies [13-17], suggesting an apparent stroke paradox for lipids [18]. To date, only one cohort study has jointly evaluated the association of several lipids with future CHD and ischemic stroke events and has suggested that lipids were also predictive of future ischemic stroke but with lower strength compared to CHD. However, this study was conducted in women only [10]. Therefore, we aimed to extend this previous analysis to compare, within the same cohort of European, middle-aged, male participants of the Prospective Epidemiological Study of Myocardial Infarction (PRIME), the relative contribution of a large panel of circulating lipid markers to the occurrence of $\mathrm{CHD}$ and ischemic stroke events as the first presentation of cardiovascular disease.

\section{Methods}

\section{Study Population}

The PRIME Study is a multicenter prospective cohort study designed to identify risk factors for CHD. Details of recruitment and the baseline examination of the PRIME Study have been described previously [19]. The target study size was to recruit 2,500 men aged 50-59 years in each of the 4 collaborating World Health Organization (WHO) Monitoring Trends and Determinants in Cardiovascular Disease (MONICA) centers in Belfast (Northern Ireland), Lille, Strasbourg and Toulouse (France). Overall, 10,602 men aged 50-59 years were recruited between 1991 and 1993 . Among them, 823 had coronary disease and 77 a history of stroke at baseline examination and were excluded from the present analysis, leaving a study population of 9,711 men (7,319 in France and 2,392 in Northern Ireland).

\section{Baseline Examination}

General Characteristics

Subjects who agreed to participate in the study were given a morning appointment and asked to fast for at least $12 \mathrm{~h}$. A full description of clinical and laboratory measurements has been published elsewhere [19]. Briefly, a self-administered health questionnaire was completed by subjects at their home and was subsequently checked by trained interviewers at the clinic. It covered a broad range of clinical information including family and personal clinical history using the Rose Questionnaire, alcohol consumption, cigarette smoking and medication use. Diabetes was defined as the current intake of oral hypoglycemic treatment or use of insulin. Blood pressure was measured with the patient in the sitting position using the same automatic device (Spengler SP9, Spengler, Cachan, France). A 12-lead electrocardiogram was also recorded.

\section{Biological Measurements}

A subset of biological measurements was performed in the entire cohort at baseline after overnight fasting. Plasma lipid analyses were centralized (SERLIA INSERM U325, Institut Pasteur de Lille, France). Total cholesterol (total-C) was measured by enzymatic methods using commercial kits in an automatic analyzer (Boehringer, Mannheim, Germany). High-density lipoprotein cholesterol (HDL-C) was determined by enzymatic methods (Boehringer) after precipitation of apolipoprotein B-containing lipoproteins. Low-density lipoprotein cholesterol (LDL-C) was calculated according to the Friedewald formula for triglycerides $\leq 4.5 \mathrm{~g} / \mathrm{l}$. Non-HDL-C was calculated using the following equation: non-HDL-C = total-C - HDL-C. Apolipoprotein (Apo) A1 and Apo B100 were quantified using commercial reagent immunonephelometry (Behringwerke, Marburg, Germany). Lipoprotein (a) $[\mathrm{Lp}(\mathrm{a})]$ was measured by a selective bi-site immunoenzymatic assay as previously described [20].

The number of men with missing lipid measurements was as follows: total-C, $\mathrm{n}=44$ (0.45\%); HDL-C, $\mathrm{n}=47$ (0.48\%); Apo A1, $\mathrm{n}=45(0.46 \%)$; Apo B100, $\mathrm{n}=45(0.47 \%)$, and Lp (a), $\mathrm{n}=50(0.51 \%)$.

\section{Follow-Up and Ascertainment of Cases}

During the 10-year follow-up, subjects were contacted annually by letter and asked to complete a clinical event questionnaire. For all subjects who reported a possible event, clinical information was sought directly from the hospital or general practitioner records. All details of electrocardiograms, computerized tomodensitometry scans, hospital admissions, cardiac enzymes, surgical intervention, angioplasty, angiography and treatments were collected. For deceased patients, the circumstances of death were obtained from the practitioner or the family whenever possible. In the few cases where the circumstances surrounding the death were not available from the practitioner or the family, death certificates were checked for supporting clinical and postmortem information on the cause of death.

Incident $\mathrm{CHD}$ and ischemic stroke events were validated by two independent medical committees. CHD events (stable and unstable angina, myocardial infarction and coronary death) were defined as previously described using clinical, biological, stress test, scintigraphic or angiographic criteria [19].

Stroke was defined according to the WHO MONICA criteria [21] as a new focal or global neurologic deficit of rapid onset and of vascular origin that persisted for more than $24 \mathrm{~h}$ (except if the symptoms were interrupted by a surgical intervention or a death). Transient ischemic attacks and strokes caused by a blood disease, a cerebral tumor or metastasis or secondary to a trauma were not considered by the stroke medical committee.

Clinical information, computerized tomodensitometry scans (compatible signs) and angiographic and autopsy data were used to evaluate and distinguish ischemic from hemorrhagic (subarachnoid or intracerebral hemorrhage) stroke events. After 10 years of follow-up, the CHD and ischemic stroke event status was available for $95.1 \%$ of the cohort. The $4.9 \%$ of men with unknown CHD and ischemic stroke event status had lower total-C, LDL-C, HDL-C and Apo A1 levels, higher Lp(a) and body mass index and 
Table 1. Baseline non-lipid risk factors according to the clinical event developed during 10 years of follow-up in the PRIME Study

\begin{tabular}{lcccc}
\hline & $\begin{array}{l}\text { No incident clinical } \\
\text { event }(\mathrm{n}=8,978)\end{array}$ & $\begin{array}{l}\text { CHD } \\
(\mathrm{n}=635)\end{array}$ & $\begin{array}{l}\text { Ischemic stroke } \\
(\mathrm{n}=98)\end{array}$ & $\begin{array}{l}\mathrm{p} \\
\text { value }\end{array}$ \\
\hline Age, years & $54.8 \pm 2.88$ & $55.3 \pm 2.93$ & $55.6 \pm 3.01$ & $<0.001$ \\
Current smoker, \% & $26.8(2,410)$ & $36.4(231)$ & $40.8(40)$ & $<0.001$ \\
Systolic blood pressure, mm Hg & $133.0 \pm 18.5$ & $140.8 \pm 21.1$ & $142.5 \pm 22.3$ & $<0.001$ \\
Diastolic blood pressure, mm Hg & $83.5 \pm 11.5$ & $87.0 \pm 12.5$ & $87.0 \pm 14.0$ & $<0.001$ \\
Antihypertensive treatment, \% & $8.8(761)$ & $15.5(92)$ & $17.4(16)$ & $<0.001$ \\
Aspirin, \% & $3.4(308)$ & $2.3(15)$ & $2.0(2)$ & 0.23 \\
Body mass index & $26.5 \pm 3.4$ & $27.3 \pm 3.6$ & $26.9 \pm 4.0$ & $<0.001$ \\
Diabetes, \% & $2.0(180)$ & $4.4(28)$ & $9.2(9)$ & $<0.001$ \\
\hline
\end{tabular}

Data are means \pm SD and percentages (numbers in parentheses) for continuous and categorical variables, respectively. $\mathrm{p}$ values are the results of global comparison across the 3 groups using Pearson $\chi^{2}$ test and ANOVA for categorical and continuous variables, respectively.

were more frequently current smokers compared to those in whom the status was known.

The study protocol was approved by the institutional review board of Broussais Hospital, Paris, France. Informed consent was obtained for each man who agreed to participate in the PRIME Study.

\section{Statistical Analysis}

Baseline characteristics in the groups of men who remained free of CHD or ischemic stroke events during the follow-up, men who developed a CHD event and men who developed an ischemic stroke event were compared using Pearson $\chi^{2}$ tests for categorical variables and ANOVA or the Kruskal-Wallis test for continuous variables, as appropriate. To account for multiple testing $(n=12$ comparisons of lipid risk factors), a Bonferroni correction was applied and a p value $<0.004$ indicated a statistically significant difference. Post hoc pair-wise comparisons of lipid risk factors between men who developed a CHD event and men who developed an ischemic stroke event were performed using the Scheffé test. The associations of each lipid parameter with future CHD and ischemic stroke were estimated in separate Cox proportional hazards models. Hazard ratios and their 95\% confidence intervals (CIs) were given for $1 \mathrm{SD}$ increase in the lipids calculated in men who remained free of clinical events during the follow-up. Analysis was systematically adjusted for study center, age, systolic blood pressure, antihypertensive treatment, current smoking status, body mass index and diabetes on an a priori basis. For the 20 men who suffered from both a CHD and an ischemic stroke event during follow-up, only the first event was considered for analysis; this group consisted of 12 men with first CHD events and 8 with first ischemic stroke events, respectively. In fact, when the occurrence of a stroke event prior to a CHD event or vice versa was taken into account using the competing risk method (the data-augmented method) [22], similar results were obtained. All comparisons were two-sided. All statistical analyses were performed using Stata software version 9.1 ${ }^{\mathrm{TM}}$ (StataCorp, College Station, Tex., USA).

\section{Results}

The mean age of the 9,711 men was $54.7 \pm 2.9$ years. After 10 years of follow-up, 635 men had a first CHD event (408 in France and 227 in Northern Ireland) and 122 had a first stroke, including 98 of ischemic origin (64 in France and 34 in Northern Ireland), 18 of hemorrhagic origin and 6 of undetermined origin. First CHD and ischemic stroke occurred a median of 5.0 years (interquartile range 2.8-7.8) and 5.4 years (interquartile range 2.7-7.6), respectively, after baseline examination.

Table 1 compares the non-lipid characteristics of those men who remained free of CHD and ischemic stroke $(n=8,978)$, those who developed a CHD event $(n=635)$ and those who had an ischemic stroke event $(n=98)$ during follow-up. As expected, men who had a clinical event (CHD or ischemic stroke) had a significantly worse cardiovascular risk profile than those who remained free of clinical events. Diabetes was twice as frequent in men with future ischemic stroke as in men with future CHD $(p=0.045)$. The mean systolic blood pressure $(p=0.48)$, antihypertensive treatment use $(\mathrm{p}=0.65)$ and aspirin use $(\mathrm{p}=0.85)$ were not statistically different between those with future ischemic stroke and those with future CHD.

Table 2 compares the mean levels of single lipids, lipid ratios and lipid-lowering treatment use between the 3 groups defined above using a Bonferroni correction that accounted for multiple testing. Whereas the proportion of men on lipid-lowering treatment, and statins in particular, did not differ between the groups, lipid levels were on average significantly higher in men who developed 
Table 2. Baseline levels of lipid markers, lipid ratios and lipid-lowering treatment use according to the clinical event developed during the 10 years of follow-up in the PRIME Study

\begin{tabular}{|c|c|c|c|c|c|}
\hline & $\begin{array}{l}\text { No incident clinical } \\
\text { event }(n=8,978)\end{array}$ & $\begin{array}{l}\text { CHD } \\
(n=635)\end{array}$ & $\begin{array}{l}\text { Ischemic stroke } \\
(\mathrm{n}=98)\end{array}$ & $\begin{array}{l}\mathrm{p} \\
\text { value }^{1}\end{array}$ & $\begin{array}{l}\mathrm{p} \\
\text { value }^{2}\end{array}$ \\
\hline Total-C, g/l & $2.21 \pm 0.38$ & $2.33 \pm 0.39$ & $2.27 \pm 0.41$ & $<0.001$ & 0.30 \\
\hline HDL-C, g/l & $0.49 \pm 0.13$ & $0.45 \pm 0.12$ & $0.48 \pm 0.13$ & $<0.001$ & 0.11 \\
\hline LDL-C, g/l & $1.43 \pm 0.33$ & $1.54 \pm 0.35$ & $1.48 \pm 0.37$ & $<0.001$ & 0.25 \\
\hline Non-HDL-C, g/l & $1.72 \pm 0.38$ & $1.88 \pm 0.40$ & $1.79 \pm 0.44$ & $<0.001$ & 0.08 \\
\hline Apo A1, g/l & $1.50 \pm 0.25$ & $1.42 \pm 0.23$ & $1.46 \pm 0.23$ & $<0.001$ & 0.28 \\
\hline Apo B100, g/l & $1.26 \pm 0.33$ & $1.41 \pm 0.37$ & $1.33 \pm 0.35$ & $<0.001$ & 0.08 \\
\hline Median Lp(a), mg/dl (25th-75th percentile) & $6.5(2.1-20)$ & $9.8(3-30)$ & $6.6(1.7-20)$ & $<0.001$ & 0.073 \\
\hline Triglycerides, $g / 1$ & $1.46 \pm 1.0$ & $1.76 \pm 1.16$ & $1.70 \pm 1.09$ & $<0.001$ & 0.72 \\
\hline Total-C/HDL-C ratio & $4.80 \pm 1.54$ & $5.54 \pm 1.69$ & $5.13 \pm 1.78$ & $<0.001$ & 0.052 \\
\hline LDL-C/HDL-C ratio & $3.11 \pm 1.13$ & $3.64 \pm 1.30$ & $3.34 \pm 1.38$ & $<0.001$ & 0.065 \\
\hline Apo B100/Apo A1 ratio & $0.87 \pm 0.27$ & $1.02 \pm 0.31$ & $0.94 \pm 0.31$ & $<0.001$ & 0.021 \\
\hline Apo B100/HDL-C ratio & $2.82 \pm 1.32$ & $3.44 \pm 1.49$ & $3.12 \pm 1.48$ & $<0.001$ & 0.08 \\
\hline Lipid-lowering treatment, \% & $8.4(750)$ & $9.8(62)$ & $9.2(9)$ & 0.45 & - \\
\hline
\end{tabular}

Except for Lp(a), data are means \pm SD and percentages (numbers in parentheses) for continuous and categorical variables, respectively.

${ }^{1}$ Global comparison across the 3 groups using Pearson $\chi^{2}$ test and ANOVA or the Kruskal-Wallis test for categorical and continuous variables, respectively; a Bonferroni correction was applied and a p value $<0.004$ indicated a statistically significant difference.

${ }^{2}$ Post hoc pair-wise comparisons between men with CHD and men with ischemic stroke events using the Scheffé test. Triglycerides were log-transformed for statistical analysis.

CHD or ischemic stroke compared to those who did not experience an incident clinical event. Moreover, the mean level of non-HDL-C, Apo B100, Lp(a) and each lipid ratio was higher and that of HDL-C lower in men with future $\mathrm{CHD}$ than in men with future ischemic stroke events, although the difference was statistically significant for the Apo B100 to Apo A1 ratio only.

The multivariate associations of total-C, HDL-C, LDL-C, non-HDL-C, triglycerides, Apo A1, Apo B100 and $\mathrm{Lp}(\mathrm{a})$ with future $\mathrm{CHD}$ and ischemic stroke are shown in figure 1 . These lipids were all highly predictive of $\mathrm{CHD}$, with comparable magnitude. Associations with ischemic stroke followed the same trend as for CHD, but were of lower strength, and none were statistically significant. However, formal comparison between the hazard ratios for $\mathrm{CHD}$ and ischemic stroke did not reach statistical significance.

The multivariate associations of lipid ratios, including total-C/HDL-C, LDL-C/HDL-C, Apo B100/Apo A1 and Apo B100/HDL-C, with CHD and ischemic stroke events are shown in figure 2. As for single lipids, lipid ratios were all predictive of $\mathrm{CHD}$, and the associations were of comparable magnitude. None of the studied lipid ratios was significantly associated with ischemic stroke events. The magnitude of their association with ischemic stroke was smaller than that for CHD. As for single lipids, however, none of the pair-wise comparisons between the hazard ratios for $\mathrm{CHD}$ and for ischemic stroke reached statistical significance. Further adjustment for baseline lipid-lowering treatment did not substantially change the results of the multivariate analyses reported in figures 1 and 2 (not shown). Among the non-lipid cardiovascular risk factors, systolic blood pressure, current smoking status and diabetes were the other independent predictors of ischemic stroke. For instance, in a model evaluating the predictive value of total- $\mathrm{C}$, the corresponding hazard ratios were 1.42 (95\% CI 1.16-1.73; $\mathrm{p}=0.001)$ for $1 \mathrm{SD}$ increase in systolic blood pressure, 1.86 (95\% CI 1.10-3.12; $\mathrm{p}=0.02)$ for current smoking and 4.59 (95\% CI $2.18-9.67$; p < 0.001) for diabetes.

\section{Additional Analyses}

In the PRIME Study, there was an attempt to classify incident ischemic stroke by subtypes. The 98 first ischemic stroke events included 39 lacunar infarctions, 27 cardioembolic infarctions, 14 atherothrombotic infarctions and 18 nonlacunar, noncardioembolic and nonatherothrombotic infarctions. In a sensitivity analysis in 


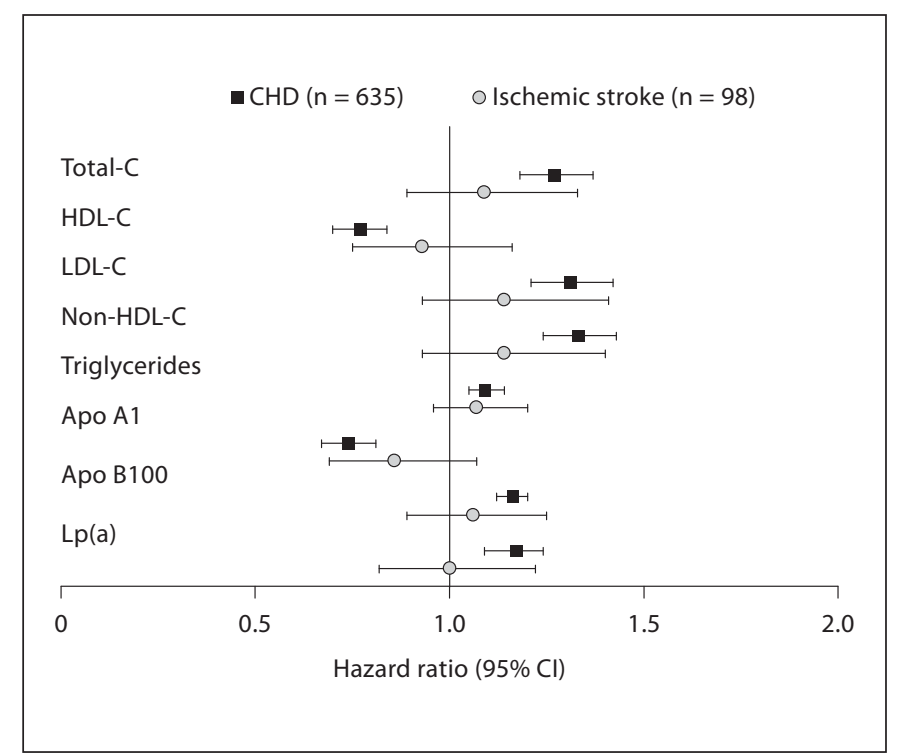

Fig. 1. Standardized adjusted hazard ratios and 95\% CIs of single lipids for CHD and ischemic stroke. Hazard ratios of each lipid variable were estimated in separate Cox proportional hazard regression models adjusted for study center, age, systolic blood pressure, antihypertensive treatment, body mass index, diabetes and smoking status. Triglycerides were log-transformed.

which cardioembolic strokes were excluded (lipids may not be related to this subtype), there was still no significant association between lipids and ischemic stroke in Cox models adjusted for age, study center and systolic blood pressure (not shown).

\section{Discussion}

The present population-based study of healthy European middle-aged men suggested that total-C, HDL-C, LDL-C, non-HDL-C, triglycerides, Apo A1 and Apo $\mathrm{B} 100$, their ratios and $\mathrm{Lp}(\mathrm{a})$ were weak predictors of ischemic stroke events over 10 years compared to their robust association with CHD events. However, it should be noted that none of the differences between the hazard ratios of lipids for $\mathrm{CHD}$ and for ischemic stroke was statistically significant.

The strong association between lipids and CHD in the current study is consistent with the well-established link between lipids and CHD [5-7]. There is an ongoing debate as to which lipid variables are the best predictors of future CHD. Apolipoproteins and the Apo B100/Apo A1

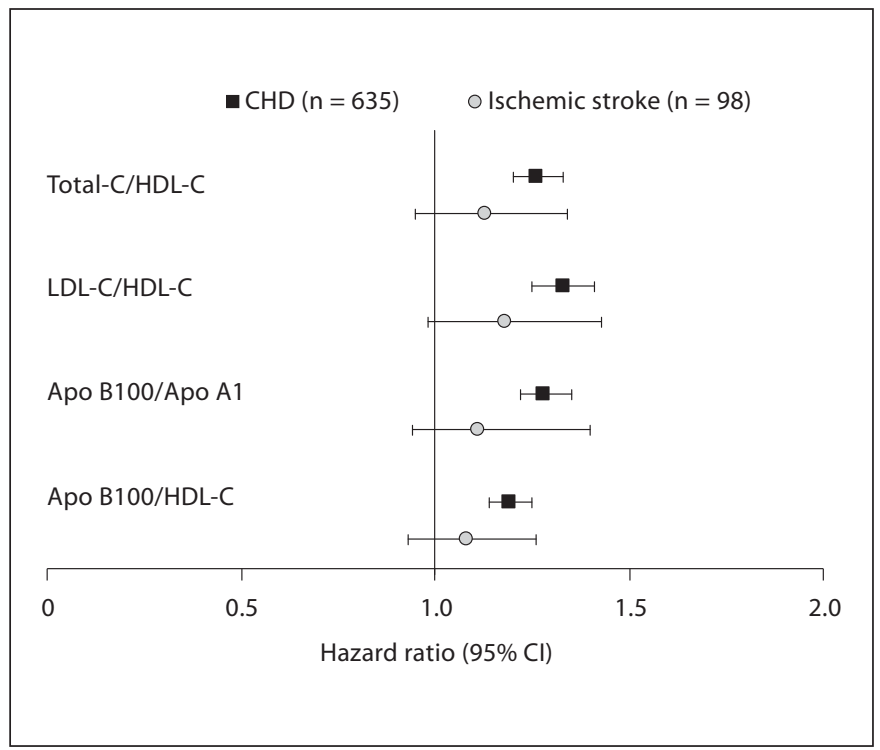

Fig. 2. Standardized adjusted hazard ratios and 95\% CIs of lipid ratios for $\mathrm{CHD}$ and ischemic stroke. Hazard ratios of each lipid variable were estimated in separate Cox proportional hazard regression models adjusted for study center, age, systolic blood pressure, antihypertensive treatment, body mass index, diabetes and smoking status.

ratio have been advocated recently in some $[23,24]$ but not all studies $[25,26]$. In our study, single lipids and apolipoproteins and their corresponding ratios were associated with $\mathrm{CHD}$, with the same order of magnitude over 10 years.

Most previous observational studies have investigated the association between 1 or 2 single lipid markers and ischemic stroke and have reported mixed results. Independent associations were found in a prospective Korean cohort [9] and in a US case-control study [12], but not in 4 large population-based prospective studies [14-17]. Furthermore, in 2 recent meta-analyses of individual data, a weak positive association between total- $\mathrm{C}$ and ischemic stroke mortality was found only in the middle-aged subjects ( $40-59$ years) or in those who were normotensive [5], while no association was observed between HDL-C and incident stroke of any type in Asians [27].

To date, only one study conducted in US participants in the Women's Health Study (WHS) has assessed the contribution of a large panel of lipids to both incident ischemic stroke and CHD events [10]. In that study, including 15,632 healthy women, of whom 132 developed 
a first ischemic stroke over 10 years of follow-up, totalC, HDL-C, non-HDL-C and LDL-C/HDL-C and total$\mathrm{C} / \mathrm{HDL}-\mathrm{C}$ ratios were predictive of ischemic stroke, whereas LDL-C, Apo A1, Apo B 100 and Apo B100/ HDL-C and Apo B100/Apo A1 ratios were not. The associations with ischemic stroke were weaker than those for CHD risk.

We have complemented the results of the WHS by conducting an analysis in men and by additionally investigating $\operatorname{Lp}(\mathrm{a})$. Consistent with the results of the WHS, we found that associations between lipids and ischemic stroke followed the same trend as those for $\mathrm{CHD}$ but were of lower magnitude. Contrary to the above study, however, none of the lipids investigated in our study were significantly associated with ischemic stroke. Three main factors may explain why we failed to observe any significant association between lipids and incident ischemic stroke events in the current study. Firstly, we may have had insufficient statistical power to detect true but smaller associations between lipids and ischemic stroke in men. However, similar negative findings were described in men in cohorts with a higher incidence of ischemic stroke events, namely the Physician's Health Study (296 ischemic stroke events in 22,071 men followed up for 11.5 years) [14] and the Atherosclerosis Risk in Communities Study (161 incident ischemic stroke events in more than 6,000 men followed up for 10 years) [15]. Secondly, ischemic stroke represents a heterogeneous condition, and the association of lipids with ischemic stroke, if any, may vary according to ischemic stroke subtype. Accordingly, total-C, LDL-C and HDL$\mathrm{C}$ have been shown to be more likely associated with atherothrombotic infarctions than with cardioembolic or lacunar infarctions $[11,12,28]$. Although investigated in a relatively small number of stroke events, we found that lipids were not associated with ischemic strokes when cardioembolic strokes were excluded in the present study. Thirdly, lipids might be associated with ischemic stroke in women but not in men (gender interaction), as suggested by the results of the EUROSTROKE collaborative project for HDL-C [13] and by those of the Atherosclerosis Risk in Communities study for triglycerides and Apo B100, respectively [15]. However, as we examined only men, this hypothesis could not be explored here.

Moreover, our data indicated that $\mathrm{Lp}(\mathrm{a})$ was not associated with ischemic stroke. A recent review of observational studies suggested that $\operatorname{Lp}(\mathrm{a})$ was an independent predictor of stroke of any type [29], but this review included transient ischemic attack, contrary to our study.
Taken together, previous and current findings suggest that the significantly reduced risk of ischemic stroke among subjects taking statin therapy observed in randomized controlled trials might be due to non-cholesterol or pleiotropic effects, possibly an anti-inflammatory effect [30-32], although this issue has been debated [33].

The strengths of the current study include its prospective design, the use of standardized criteria to define clinical events within the same population and the investigation of a large panel of lipids. However, the study does have some limitations that should be mentioned. As noted above, our study may have lacked statistical power to detect a true but small association of lipids with ischemic stroke events. LDL-C is a heterogeneous group of particles varying in size, and small dense LDL particles have recently been found to be associated with an increased risk of first-ever stroke of thrombotic and hemorrhagic origin [34]. However, small dense LDL particles were not measured in the PRIME Study. No interim examinations were performed in the PRIME Study, so that changes in lipid levels and in lipid-lowering treatment during followup were not controlled for. The PRIME Study consisted of healthy middle-aged men, and thus the applicability of the current findings to women and elderly populations needs to be evaluated.

\section{Conclusion}

The present population-based study suggests that circulating lipids were weak predictors of ischemic stroke in healthy middle-aged men, contrasting with their robust association with CHD.

\section{Appendix}

The PRIME Study Group

The PRIME Study is organized under an agreement between INSERM and the Merck, Sharp and Dohme-Chibret Laboratory, with the following participating laboratories:

- The Strasbourg MONICA Project, Laboratoire d'Épidémiologie et de Santé Publique, EA 3430, Strasbourg, and Université de Strasbourg, Strasbourg, France (D. Arveiler, B. Haas);

- The Toulouse MONICA Project, INSERM, U558, and Department of Epidemiology, Université Paul Sabatier - Toulouse Purpan, Toulouse, France (J. Ferrieres, J.B. Ruidavets);

- The Lille MONICA Project, INSERM, U744, Lille, Institut Pasteur de Lille, Lille, and Université Lille Nord de France, Lille, France (P. Amouyel, M. Montaye);

- Department of Epidemiology and Public Health, Queen's University, Belfast, UK (A. Evans, J. Yarnell, F. Kee); 
- Department of Atherosclerosis, INSERM, U545, Lille, Institut Pasteur de Lille, Lille, and Faculté de Médecine, Université Lille Nord de France, Lille, France (G. Luc, J.M. Bard);

- Laboratory of Hematology, INSERM, U626, Hôpital La Timone, Marseille, France (I. Juhan-Vague, P. Morange);

- Laboratory of Endocrinology, INSERM, U563, Toulouse, France (B. Perret);

- Vitamin Research Unit, University of Bern, Bern, Switzerland (F. Gey);

- The Nutrition and Metabolism Group, Center for Public Health, Queen's University, Belfast, UK (J. Woodside, I. Young);

- DNA Bank, INSERM/UPMC, Paris University UMRS 937, Paris, France (F. Cambien);

- The Coordinating Center, Paris-Sud XI University, Villejuif, France (P. Ducimetiere);

- INSERM, Unit 970, Villejuif, and Université Paris V, Paris Cardiovascular Research Center, Paris, France (A. Bingham).

\section{Acknowledgements}

We thank the following organizations which allowed the recruitment of the PRIME subjects: the health screening centers organized by the Social Security of Lille (Institut Pasteur), Strasbourg, Toulouse and Tourcoing; the Occupational Medicine Services of Haute-Garonne, of the Urban Community of Strasbourg; the Association Inter-entreprises des Services Médicaux du Travail de Lille et environs; the Comité pour le Développement de la Médecine du Travail; the Mutuelle Générale des PTT du BasRhin; the Laboratoire d'Analyses de l'Institut de Chimie Biologique de la Faculté de Médecine de Strasbourg, and the Department of Health and Social Services and Personal Safety (NI), its Research and Development Office and the Northern Ireland Chest Heart and Stroke Association.

We also thank the members of the event validation committees: Prof. L. Guize, Dr. C. Morrison, Dr. M.-T. Guillanneuf and Prof. M. Giroud. We would like to thank the Alliance Partnership Program for its financial support. We finally thank Aurelien Belot for his statistical support.

The PRIME Study was funded by INSERM and the Merck, Sharp and Dohme-Chibret Laboratories.

\section{References}

1 Baigent C, Keech A, Kearney PM, Blackwell L, Buck G, Pollicino C, Kirby A, Sourjina T, Peto R, Collins R, Simes R: Efficacy and safety of cholesterol-lowering treatment: prospective meta-analysis of data from 90,056 participants in 14 randomised trials of statins. Lancet 2005;366:1267-1278.

$\checkmark 2$ Colhoun HM, Betteridge DJ, Durrington PN, Hitman GA, Neil HA, Livingstone SJ, Thomason MJ, Mackness MI, Charlton-Menys V, Fuller JH: Primary prevention of cardiovascular disease with atorvastatin in type 2 diabetes in the Collaborative Atorvastatin Diabetes Study (CARDS): multicentre randomised placebo-controlled trial. Lancet 2004;364:685-696.

- 3 Collins R, Armitage J, Parish S, Sleight P, Peto R: Effects of cholesterol-lowering with simvastatin on stroke and other major vascular events in 20,536 people with cerebrovascular disease or other high-risk conditions. Lancet 2004;363:757-767.

-4 Amarenco P, Labreuche J, Lavallée P, Touboul PJ: Statins in stroke prevention and carotid atherosclerosis: systematic review and up-to-date meta-analysis. Stroke 2004; 35:2902-2909.

-5 Lewington S, Whitlock G, Clarke R, Sherliker P, Emberson J, Halsey J, Qizilbash N, Peto $\mathrm{R}$, Collins R: Blood cholesterol and vascular mortality by age, sex, and blood pressure: a meta-analysis of individual data from 61 prospective studies with 55,000 vascular deaths. Lancet 2007;370:1829-1839.
-6 Sharrett AR, Ballantyne CM, Coady SA, Heiss G, Sorlie PD, Catellier D, Patsch W: Coronary heart disease prediction from lipoprotein cholesterol levels, triglycerides, lipoprotein(a), apolipoproteins A-I and B, and HDL density subfractions: the Atherosclerosis Risk in Communities (ARIC) Study. Circulation 2001;104:1108-1113.

$\checkmark 7$ Wilson PW, D'Agostino RB, Levy D, Belanger AM, Silbershatz H, Kannel WB: Prediction of coronary heart disease using risk factor categories. Circulation 1998;97:18371847.

8 Fuentes B, Martínez-Sánchez P, Díez-Tejedor E: Lipid-lowering drugs in ischemic stroke prevention and their influence on acute stroke outcome. Cerebrovasc Dis 2009; 27(suppl 1):126-133.

-9 Ebrahim S, Sung J, Song YM, Ferrer RL, Lawlor DA, Davey Smith G: Serum cholesterol, haemorrhagic stroke, ischaemic stroke, and myocardial infarction: Korean national health system prospective cohort study. BMJ 2006;333:22.

10 Everett BM, Kurth T, Buring JE, Ridker PM The relative strength of $\mathrm{C}$-reactive protein and lipid levels as determinants of ischemic stroke compared with coronary heart disease in women. J Am Coll Cardiol 2006;48: 2235-2242.

11 Sacco RL, Benson RT, Kargman DE, BodenAlbala B, Tuck C, Lin IF, Cheng JF, Paik MC, Shea S, Berglund L: High-density lipoprotein cholesterol and ischemic stroke in the elderly: the Northern Manhattan Stroke Study. JAMA 2001;285:2729-2735.
12 Tirschwell DL, Smith NL, Heckbert SR, Lemaitre RN, Longstreth WT Jr, Psaty BM: Association of cholesterol with stroke risk varies in stroke subtypes and patient subgroups. Neurology 2004;63:1868-1875.

13 Bots ML, Elwood PC, Nikitin Y, Salonen JT, Freire de Concalves A, Inzitari D, Sivenius J, Benetou V, Tuomilehto J, Koudstaal PJ, Grobbee DE: Total and HDL cholesterol and risk of stroke. EUROSTROKE: a collaborative study among research centres in Europe. J Epidemiol Community Health 2002;56 (suppl 1):i19-i24.

14 Bowman TS, Sesso HD, Ma J, Kurth T, Kase CS, Stampfer MJ, Gaziano JM: Cholesterol and the risk of ischemic stroke. Stroke 2003; 34:2930-2934.

15 Shahar E, Chambless LE, Rosamond WD, Boland LL, Ballantyne CM, McGovern PG, Sharrett AR: Plasma lipid profile and incident ischemic stroke: the Atherosclerosis Risk in Communities (ARIC) study. Stroke 2003;34:623-631.

16 Wolf PA, D’Agostino RB, Belanger AJ, Kannel WB: Probability of stroke: a risk profile from the Framingham Study. Stroke 1991;22: 312-318.

17 Assmann G, Schulte H, Cullen P, Seedorf U: Assessing risk of myocardial infarction and stroke: new data from the Prospective Cardiovascular Münster (PROCAM) study. Eur J Clin Invest 2007;37:925-932.

18 Amarenco P, Steg PG: The paradox of cholesterol and stroke. Lancet 2007;370:18031804. 
19 Ducimetiere P, Ruidavets JB, Montaye M, Haas B, Yarnell J: Five-year incidence of angina pectoris and other forms of coronary heart disease in healthy men aged 50-59 in France and Northern Ireland: the Prospective Epidemiological Study of Myocardial Infarction (PRIME) Study. Int J Epidemiol 2001;30:1057-1062.

-20 Luc G, Bard JM, Arveiler D, Ferrieres J, Evans A, Amouyel P, Fruchart JC, Ducimetiere P; PRIME Study Group: Lipoprotein (a) as a predictor of coronary heart disease: the PRIME Study. Atherosclerosis 2002;163: 377-384.

-21 Thorvaldsen P, Asplund K, Kuulasmaa K, Rajakangas AM, Schroll M: Stroke incidence, case fatality, and mortality in the WHO MONICA project. World Health Organization Monitoring Trends and Determinants in Cardiovascular Disease. Stroke 1995;26:361-367.

-22 Lunn M, McNeil D: Applying Cox regression to competing risks. Biometrics 1995;51:524532.

-23 McQueen MJ, Hawken S, Wang X, Ounpuu S, Sniderman A, Probstfield J, Steyn K, Sanderson JE, Hasani M, Volkova E, Kazmi K, Yusuf S: Lipids, lipoproteins, and apolipoproteins as risk markers of myocardial infarction in 52 countries (the INTERHEART study): a case-control study. Lancet 2008; 372:224-233.
24 Sierra-Johnson J, Fisher RM, Romero-Corral A, Somers VK, Lopez-Jimenez F, Ohrvik J, Walldius G, Hellenius ML, Hamsten A: Concentration of apolipoprotein $\mathrm{B}$ is comparable with the apolipoprotein B/apolipoprotein A-I ratio and better than routine clinical lipid measurements in predicting coronary heart disease mortality: findings from multi-ethnic US population. Eur Heart J 2009;30:710-717.

25 Ingelsson E, Schaefer EJ, Contois JH, McNamara JR, Sullivan L, Keyes MJ, Pencina MJ, Schoonmaker C, Wilson PW, D’Agostino RB, Vasan RS: Clinical utility of different lipid measures for prediction of coronary heart disease in men and women. JAMA 2007;298: 776-785.

26 van der Steeg WA, Boekholdt SM, Stein EA, El-Harchaoui K, Stroes ES, Sandhu MS, Wareham NJ, Jukema JW, Luben R, Zwinderman AH, Kastelein JJ, Khaw KT: Role of the apolipoprotein B-apolipoprotein A-I ratio in cardiovascular risk assessment: a casecontrol analysis in EPIC-Norfolk. Ann Intern Med 2007; 146:640-648.

27 Woodward M, Barzi F, Feigin V, Gu D, Huxley R, Nakamura K, Patel A, Ho S, Jamrozik $\mathrm{K}$ : Associations between high-density lipoprotein cholesterol and both stroke and cor onary heart disease in the Asia Pacific region. Eur Heart J 2007;28:2653-2660.
28 Imamura T, Doi Y, Arima H, Yonemoto K, Hata J, Kubo M, Tanizaki Y, Ibayashi S, Iida M, Kiyohara Y: LDL cholesterol and the development of stroke subtypes and coronary heart disease in a general Japanese population: the Hisayama study. Stroke 2009;40: 382-388.

29 Smolders B, Lemmens R, Thijs V: Lipoprotein (a) and stroke: a meta-analysis of observational studies. Stroke 2007;38:1959-1966.

30 Amarenco P, Moskowitz MA: The dynamics of statins: from event prevention to neuroprotection. Stroke 2006;37:294-296.

31 Bea F, Blessing E, Bennett B, Levitz M, Wallace EP, Rosenfeld ME: Simvastatin promotes atherosclerotic plaque stability in apoE-deficient mice independently of lipid lowering. Arterioscler Thromb Vasc Biol 2002;22:1832-1837.

32 Vivancos-Mora J, Gil-Nunez A: Lipids and stroke: the opportunity of lipid-lowering treatment. Cerebrovasc Dis 2005:20(suppl 2):53-67.

33 Robinson JG, Smith B, Maheshwari N, Schrott H: Pleiotropic effects of statins: benefit beyond cholesterol reduction? A metaregression analysis. J Am Coll Cardiol 2005; 46:1855-1862.

>34 Cui YH, Fan Q, Wang PH, Hui R, Cianflone K, Wang DW: Small dense low-density lipoproteins and associated risk factors in patients with stroke. Cerebrovasc Dis 2009;27: 99-104. 